\title{
Study of Some Predictors of Severe Hemolysis in Children with Glucose-6-Phosphate Dehydrogenase Deficiency
}

\author{
SEHAM M. RAGAB, M.D.*; MOHAMMAD A. HELWA, M.D.** and EMAD A. MAHDY, M.Sc.* \\ The Departments of Pediatrics* and Clinical Pathology**, Faculty of Medicine, Menoufia University, Menoufia, Egypt
}

\begin{abstract}
Background: Glucose-6-Phosphate Dehydrogenase (G6PD) deficiency is one of the most common inherited disorders of mankind; more than 400 million people are affected worldwide, and it is a major health problem in Egypt.

Aim of Work: To study some predictors of severe hemolysis in children with glucose-6-phosphate dehydrogenase deficiency and the degree of DNA damage in these patients.

Patients and Methods: Seventy-two patients with G6PD deficiency admitted with acute hemolytic attacks to Diarb Negm Central Hospital-Sharkia Governorate, Egypt-over a period of 1 year from 1 st May 2014 to 30 th April 2015. We collected demographic data, details of signs and symptoms; special attention was given to history of fava bean ingestion, history of drug use or history of recent infection, history of neonatal jaundice, family history of G6PD deficiency disease, abdominal pain, vomiting or fever at admission and the results of tests for hemoglobin, reticulocytic count, hepatic function, G6PD enzyme activity and detection of DNA damage by DNA extraction, purification and agarose gel electrophoresis. We classified patients into mild and severe groups based on hemoglobin levels at admission. The mild cases were considered as the control group.
\end{abstract}

Results: 72 children with G6PD deficiency admitted with acute hemolytic attacks were included in this study, 52 (72\%) patients with severe hemolysis and $20(28 \%)$ patients with mild hemolysis (control group). There were no statistically significant differences in many factors between the two groups, but some factors were detected to have statistical significance for severe hemolysis included younger age $(p<.0001)$, male gender $(p<.0001)$, presence of fever at admission $(p<.0001)$, presence of vomiting $(p<.0001)$ and abdominal pain $(p<.0001)$ during the attack, higher Alkaline Phosphatase (ALP) ( $p$ $<.0001)$, Aspartate Aminotransferase (AST) $(p<.0001)$, Lactate Dehydrogenase (LDH) $(p<.0001)$ and Total Serum Bilirubin (TSB) $(p<.05)$. DNA damage was significantly higher in the severe cases compared to the mild cases $(p<.0001)$.

Conclusion: Severe hemolysis can be predicted during hemolytic episodes in children with G6PD deficiency by young age, male gender, the presence of abdominal pain, vomiting and fever, high levels of ALP, AST, LDH enzymes

Correspondence to: Dr. Seham M. Ragab, The Department of Pediatrics, Faculty of Medicine, Menoufia University, Menoufia, Egypt and elevated TSB. This severe hemolysis predisposes patients to higher degree of DNA damage.

Key Words: Predictors of severe hemolysis - G6PD - ALP $-L D H-D N A$

\section{Introduction}

GLUCOSE-6-Phosphate Dehydrogenase (G6PD) is a ubiquitously expressed enzyme that has a housekeeping role in all cells and is particularly critical to the integrity and functioning of Red Blood Cells (RBCs). The G6PD gene has many mutant alleles which entail a decrease in enzyme activity, expressing the G6PD deficient phenotype. This trait is widespread in many human populations in whom several of the underlying mutant alleles are present at variable polymorphic frequencies [1]. G6PD is an enzyme that catalyzes the first reaction in the pentose phosphate pathway, providing reducing power to all cells in the form of reduced form of Nicotinamide Adenine Dinucleotide Phosphate (NADPH). NADPH enables cells to counterbalance oxidative stress that can be triggered by several oxidant agents, and to preserve the reduced form of glutathione. Since red blood cells do not contain mitochondria, the pentose phosphate pathway is their only source of NADPH; therefore, defense against oxidative damage is dependent on G6PD [2]. G6PD deficiency is the most common hereditary enzyme deficiency reported so far [3]. This enzyme deficiency has affected more than 400 million people around the world. Due to the process of the natural selection, most cases of illness are observed in tropical regions of Africa, the Middle East, tropical and subtropical regions of Asia and the Mediterranean basin [4] There are 186 different mutations in the G6PD gene, found at the q28 locus on the X chromosome, that have been identified and can lead to G6PD deficiency mainly through a decrease in the stability of the enzyme. The result is a range of G6PD 
phenotypes, ranging from severe to mild enzyme deficiency or even normal enzyme activity. Deficiency is mainly manifested in hemizygous males, with heterozygous females displaying varying levels of enzyme deficiency and homozygous deficient females being rare [5]. Severe hemolysis in patients with glucose-6-phosphate dehydrogenase deficiency can be predicted during hemolytic episodes in children with low G6PD by young age, male gender, a negative family history of G6PD deficiency, the presence of fever and vomiting and a high Alkaline Phosphatase (ALP) enzyme [6] Increased Deoxyribonucleic Acid (DNA) damage may be the result of deficient detoxification of reactive oxygen species by glutathione and may ultimately account for the higher rate of apoptosis in G6PD-deficient mononuclear cells [7]. Data about predictors of the severity of hemolysis and the reflection on DNA damage among G6PD deficient children are scarce, hence this work was designed.

Aim of study: To study some predictors of severe hemolysis in children with glucose-6-phosphate dehydrogenase deficiency and the degree of DNA damage in these patients.

\section{Patients and Methods}

This study included 72 children with G6PD deficiency (66 males and 6 females) attended to Emergency Department of Diarb Negm Hospital, Sharkia Governorate, Egypt; with an acute hemolytic attack at the period starting from 1 st May 2014 to 30 th April 2015, their ages ranged from 1.5-13 years, all patients were confirmed cases of G6PD deficiency (previously diagnosed or recently diagnosed). According to their hemoglobin level at the time of admission the studied patients subdivided into 2 groups $[6,8]$ : To assess the predictors of severity, patients were divided into two groups based only on their hemoglobin at the time of admission. If it was less than $\leq 5 \mathrm{~g} / \mathrm{dl}$, it was regarded as severe hemolysis and if more it was regarded as mild hemolysis.

Inclusion criteria: Patients presented with a suggesting history and clinical picture of acute hemolysis and low hemoglobin level and either known cases of G6PD deficiency or expected to be G6PD deficient to be confirmed later by enzyme activity assay.

Exclusion criteria: Patients presented with clinical picture of acute hemolysis due to other causes of acute hemolysis (auto immune hemolytic anemia).
Included patients were subjected to detailed history and through clinical examination, in history, special emphasis was given to age, sex, residency and social level, history of recent fava beans ingestion, history and type of recent drug intake or chemical exposure, history of recent infection, presence of fever, abdominal pain or vomiting, past history of neonatal jaundice, family history of the disease.

Laboratory investigations: Laboratory investigations included $\mathrm{CBC}$ and reticulocytic count using AC920 Autocounter, quantitative colorimetric measurement of serum Alkaline Phosphatase (ALP), Alanine Aminotransferase (ALT), Aspartate Aminotransferase (AST), Lactate Dehydrogenase $(\mathrm{LDH})$ and Total Serum Bilirubin (TSB).

Quantitative determination of G6PD enzyme level in the red blood cells by Microlab 300 .

Fresh EDTA blood samples were digested with Proteinase K enzyme, ribonucleic acid (RNA) was removed with RNase A enzyme. The lysate was then purified, washed and centrifuged till leukocytes DNA was extracted. The extracted total DNA was checked by agarose gel electrophoresis. The respective DNA appears as sharp intact bands while damaged DNA appears as diffuse fragmented bands.

Statistical analysis: The data were processed on an IBM-PC compatible computer using SPSS Version 16 (SPSS Inc., Chicago, IL, USA). Continuous variables were presented as mean $\pm \mathrm{SD}$, while for categorical variables, numbers $(\%)$ were used. Chi-square $\left(\chi^{2}\right)$ test was used for comparison of the categorical variables. Student's $t$-test was used to compare continuous parametric variables in the two groups. While MannWhitney (U) was used for comparing non-parametric variables in the two groups. Correlation Coefficient ( $r$ ) between two quantitative variables. All tests were two-tailed and $p$-value $<0.05$ was considered statistically significant.

\section{Results}

Seventy-two patients with G6PD deficiency admitted with acute hemolytic attacks were included in this study, $52(72.2 \%)$ presented with severe hemolysis and $20(27.8 \%)$ presented with mild hemolysis (control group). Sudden pallor and passage of dark or cola-colored urine were universal presenting symptoms for all cases. A marked elevation in serum bilirubin coinciding with intravascular hemolysis was a feature in all cases. Incriminating factors responsible for hemolysis included 
ingestion or exposure to fava beans $(90.3 \%)$, drug intake $(4.2 \%)$ and infection $(5.5 \%)$, with more than one predisposing factor existing in some children, though no significant difference detected between the 2 groups regarding the predisposing factor. There was no statistically significant difference between both groups regarding family history of G6PD deficiency disease, history of neonatal hyperbilirubinemia and ALT levels. G6PD patients with severe hemolysis were significantly younger than those with mild hemolysis. Severe hemolysis was significantly predominant in males. Presence of abdominal pain, vomiting or fever at time of admission were high significantly presented in G6PD patients with severe hemolysis.

Laboratory results associated with significantly higher hemolysis compared to mild cases included diminished G6PD enzyme activity, high reticulocytes count\%, elevated serum levels of ALP, AST, LDH and TSB. Significant higher degree of DNA damage was present in severe cases (Table 1).

Table (1): Clinical characteristics, laboratory parameters analysis of studied groups.

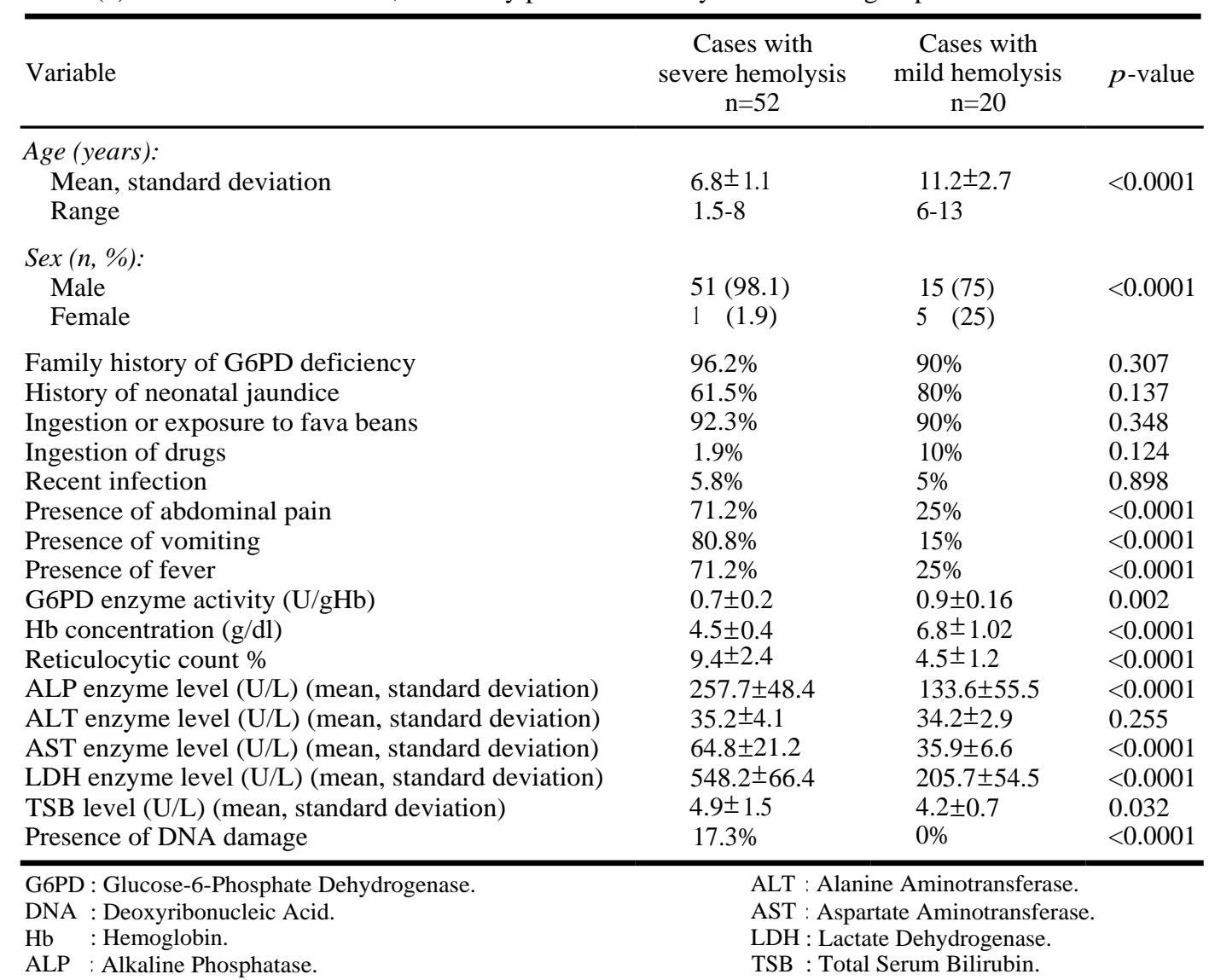

\section{Discussion}

G6PD deficiency is the most common human enzyme defect, being present in more than 400 million people worldwide [4,9]. In Egypt, which lies in a special geographical situation at the meeting of 3 continents with a variety of ethnic groups, the prevalence of G6PD deficiency is about 5.9\% [10]. A study done at 2017 revealed that the incidence of hospital admissions in Egypt for acute hemolysis due to G6PD deficiency with hemoglobin less than $6 \mathrm{~g} / \mathrm{dl}$ is $9.27 \%$ of total admissions [11] hence our study was done to detect some predictors of severe hemolysis in children with G6PD defi- ciency involving some parameters in history, symptoms, signs and laboratory investigations, and the degree of DNA damage in these patients. The present study included a total number of 72 G6PD deficient patients who were admitted with acute hemolysis. Patients were divided into 2 groups; group I included those with severe hemolysis with hemoglobin $\leq 5 \mathrm{~g} / \mathrm{dl}$ and group II included those with mild hemolysis with hemoglobin $>5 \mathrm{~g} / \mathrm{dl}$. Considering a $5 \mathrm{~g} / \mathrm{dl}$ hemoglobin level as a sharp differentiating point between the two groups $[\mathbf{6 , 8}]$ Our study revealed that young age $<7$ years is a significant predictor of severe hemolysis in G6PD patients, younger patients are probably exposed to 
more than one incriminating factor and it is the time for introducing fava beans and probably several drugs for first time. Infections are very common in young childhood thus infection-induced hemolysis is a common cause of clinically significant hemolysis. Many different types of infections may cause significant hemolysis in the G6PD deficient patients [12]. The mechanism by which this occurs is not clear, but it has been suggested that during phagocytosis, discharging active oxygen species occurs [13]. Our study revealed that the frequency of the enzyme deficiency in males was higher than in females, this result reflects the X-linked mode of inheritance of G6PD deficiency $[\mathbf{1 4 , 1 5}$. Our results showed that male gender is a significant predictor for severe hemolysis as all cases with severe hemolysis were males except one case only was female. The results of our study revealed that abdominal pain and vomiting are highly significant predictors of severe hemolysis in G6PD deficient children. Gastric upset, abdominal pain, and vomiting are associated with severe hemolysis due to Nitric Oxide (NO) depletion due to consumption of NO by plasma free [16]. Our results showed that fever was also a significant predictor of severe hemolysis in children with G6PD deficiency, due to the release of humble of pyrogens during the process of hemolysis and the accompanying infection in many cases [6]. Our results showed that elevated ALP enzyme level is a significant predictor of severe hemolysis in patients of G6PD deficiency. Alkaline phosphatase enzyme is found in all cells including red blood cells and is released to plasma upon the destruction of these cells, therefore it could be used as an early marker of hemolysis of red blood cells [17]. Our results showed that elevated TSB is a significant predictor of severe hemolysis in patients with G6PD deficiency as it was significantly high in G6PD patients with severe hemolysis than others with mild to moderate hemolysis, severe hemolysis may result in rapidly rising serum total bilirubin (TSB) levels, with the potential of extreme hyperbilirubinemia [18]. Our results showed significant elevation in AST enzyme level in patients with severe hemolysis due to G6PD deficiency with no significant elevation of ALT enzyme level compared to others with mild hemolysis, hemolysis can cause a significant increase in AST and a moderate increase in ALT owing to the release of these transaminases from the hemolyzed erythrocytes, as there is more AST than ALT in RBCs, a high AST-to-ALT ratio would be expected in a case of severe hemolysis [19]. Our results showed that Lactate Dehydrogenase (LDH) enzyme level is a significant predictor of severe hemolysis in patients with G6PD deficiency as it was signifi- cantly high in G6PD patients with severe hemolysis than others with mild hemolysis.

Considering the importance of G6PD reaction and its products NADPH and Glutathione (GSH) against oxidative stress, the failure of detoxification of $\mathrm{H}_{2} \mathrm{O}_{2}$ in G6PD deficient white blood cells could probably induce primary DNA damage [20]. In our study 9 patients out of group I with severe hemolysis had DNA damage, DNA integrity was examined after DNA extraction, purification and electrophoresis while no patient had DNA damage of group II with mild hemolysis.

In a study done in Jordan at 2009 on predictors of severe hemolysis in G6PD deficient children [6], they concluded that severe hemolysis can be predicted during hemolytic episodes in children with low G6PD by young age, male gender, a negative family history of the disease, the presence of fever, abdominal pain and vomiting and a high ALP. Our results meet with this study results except for the family history of the disease, though our study demonstrated more laboratory predictors as high AST, LDH and TSB.

This is the first study to demonstrate presence of DNA damage as a predictor of severe hemolysis in G6PD deficient children.

\section{Conclusions:}

We identified some factor which can predict severe hemolysis in children with G6PD deficiency during acute hemolytic attacks as young age, male gender, the presence of abdominal pain, vomiting and fever during the attack, high levels of ALP, AST, LDH enzymes, elevated TSB, and detection of DNA damage.

\section{References}

1- HOWES R.E., PIEL F.B., PATIL A.P., NYANGIRI O.A., GETHING P.W., HOGG M.M., BATTLE K.E., PADILLA C.D., BAIRD J.K. and HAY S.I.: G6PD deficiency prevalence and estimates of affected populations in malaria endemic countries, a geostatistical model-based map. PLoS Med., 9 (11): e1001339, 2012.

2- LUZZATTO L., METHA A. and VULLIAMY T.: Glucose 6-phosphate dehydrogenase deficiency. In: Scriver CR, Beaudet AL, Sly WS, et al., eds. The metabolic and molecular bases of inherited disease, 8 th edn. Columbus: McGraw-Hill: 4517553, 2001.

3- SODEINDE O.: Glucose-6-phosphate dehydrogenase deficiency. Baillieres Clin. Haematol., 5 (2): 367-82, 1992.

4- CAPPELLINI M.D. and FIORELLI G.: Glucose-6phosphate dehydrogenase deficiency, Lancet, 371: 6474, 2008. 
5- HIRONO A., KAWATE K., HONDA A., FUJII H. and MIWA S.: A single mutation $202 \mathrm{G}>\mathrm{A}$ in the human glucose-6-phosphate dehydrogenase gene (G6PD) can cause acute hemolysis by itself. Blood, 99: 1498-9, 2002.

6- AL SWEEDAN S.A., JDAITAWI H., KHRIESAT W.M., KHADER Y.Y. and AL-RIMAWI H.S.: Predictors of Severe Hemolysis in Patients with Glucose-6-phosphate Dehydrogenase Deficiency following Exposure to Oxidant Stresses. Hematology/Oncology and Stem Cell Therapy, 2 (2): 354-7, 2009

7- EFFERTH T., FABRY U. and OSIEKA R.: DNA damage and apoptosis in mononuclear cells from glucose-6phosphate dehydrogenase deficient patients (G6PD Aachen variant) after UV irradiation. J. Leukoc. Biol., 69 (3): 340-2, 2001.

8- SHEKALAGHE S.A., BRAAK R., DAOU M., KAVISHE R., VAN DEN BIJLLAARDT W., VAN DEN BOSCH S., KOENDERINK J.B., LUTY A.J., WHITTY C.J., DRAKELEY C., SAUERWEIN R.W. and BOUSEMA T.: In Tanzania, hemolysis after a single dose of primaquine coadministered with an artemisinin is not restricted to glucose-6-phosphate dehydrogenase-deficient (G6PD A) individuals. Antimicrob. Agents Chemother., 54: 17628, 2010.

9- AINOON O., BOO N.Y., YU Y.H., CHEONG S.K., HAMIDAH H.N. and LIM J.H.: Complete molecular characterization of glucose-6-phosphate dehydrogenase (G6PD) deficiency in a group of Malaysian Chinese neonates. Malays. J. Pathol., 26: 89-98, 2004.

10- HUSSEIN L., YAMAMAH G. and SALEH A.: Glucose6-phosphate dehydrogenase deficiency and sulfadimidin acetylation phenotypes in Egyptian oases. Biochemical Genetics, 30 (3-4): 113-21, 1992.

11- AHMED A.Y. and SAAD A.H.: Admissions and Mortality in an Egyptian Paediatric Tertiary Care Hospital. Egyptian Pediatric Association Gazette, 65: 25-9, 2017.

12- LUZZATTO L., NANNELLI C. and NOTASO R.: Glucose-6-phosphate dehydrogenase deficiency. Hematology/ Oncology Clinics of North America, 30: 373-93, 2016.
13- CLANCY R.M., LEVARTOVSKY D., LESZCZYNSKAPIZIAK J., YEGUDIN J. and ADRAMSON S.B.: Nitric oxide reacts with intracellular glutathione and activates the hexose monophosphate shunt in human neutrophils: Evidence for S-nitrosoglutathione as a bioactive intermediary. Proc. Natl. acad. Sci. USa., 91: 3680, 1994.

14- JOSHI S.R., PATEL R.Z., PATEL H.R., SUKUMAR S. and COLAH R.B.: High prevalence of G6PD deficiency in Vataliya Prajapati community in western India. Haematologia, 31 (1): 57-60, 2001.

15- SANPAVAT S., NUCHPRAYOON I., KITTIKALAYAWONG A. and UNGBUMNET W.: The value of methemoglobin reduction test as a screening test for neonatal glucose 6-phosphate dehydrogenase deficiency. J. Med. Assoc. Thai., 84 (1): 91-8, 2001.

16- GLADWIN M.T., SCHECHTER A.N., OGNIBENE F.P., COLES W.A., REITER C.D., SCHENKE W.H., CSAKO G., WACLAWIW M.A., PANZA J.A. and CANNON III R.O.: Divergent nitric oxide bioavailability in men and women with sickle cell disease. Circulation, 107: 271-8, 2003.

17- NALBANTOGLU A., OVALI F. and NALBANTOGLU B.: Alkaline phosphatase as an early marker of hemolysis in newborns. Pediatrics International, 53: 936-8, 2011.

18- KAPLAN M. and HAMMERMAN C.: Severe neonatal hyperbilirubinemia: A potential complication of glucose6-phosphate dehydrogenase deficiency. Clin. Perinatol., 25: 575-90, 1998 .

19- DUFOUR D.R., LOTT J.A., NOLTE F.S., GRETCH D.R., KOFF R.S. and SEEFF L.B.: Diagnosis and monitoring of hepatic injury. I. Performance characteristics of laboratory tests. Clin. Chem., 46: 2027-49, 2000.

20- ASENSI M., SASTRE J., PALLARDO F.V., LLORET A., LEHNER M., GARCIA-De-La ASUNCION J. and VIÑA J.: Ratio of reduced to oxidized glutathione as indicator of oxidative stress status and DNA damage. Methods in Enzymology, 299: 267-76, 1999. 


\section{دراسة لبعض تنبؤات شدة إنحلال الدم فى الآطفال الذين يعانون من نقص إنزيم جلوكوز}

الهدف من البحش: دراسة بعض تتبؤات شدة إنحلال الدم فى الآطفال المصابين بمرض نقص إنزيم جلوكوز 7 فوسفات النازع الهيدوجين

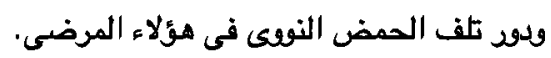

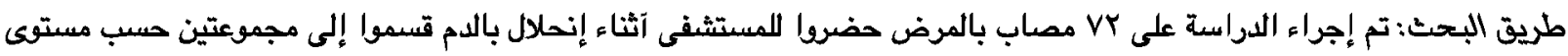

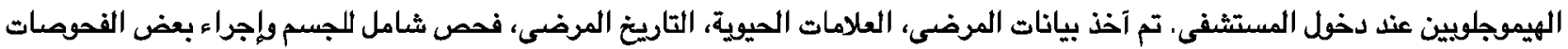
المعملية.

نتائج البحث: تبين من البحث آن هناك فرق واضِ بين المجموعتين من حيث عمر المريض، نوعه، وجود آعراض مصاحبة آثناء إنصلال

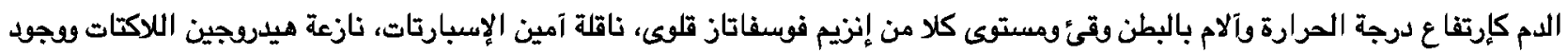
إعتلال بالحمض النونى لورتئ.

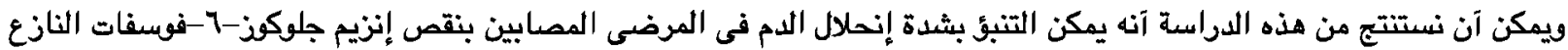

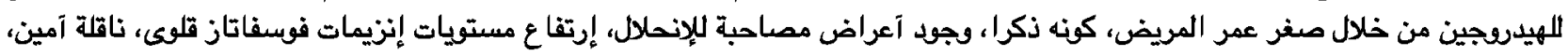

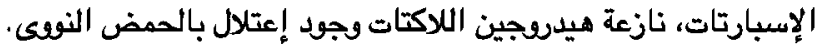

